\title{
Incidence, Reproductive Outcome, and Economic Impact of Reciprocal Translocations in the Domestic Pig
}

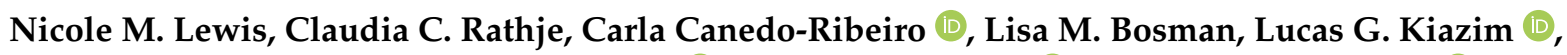

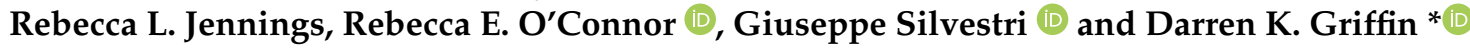

check for

updates

Citation: Lewis, N.M.; Rathje, C.C.; Canedo-Ribeiro, C.; Bosman, L.M.;

Kiazim, L.G.; Jennings, R.L.;

O'Connor, R.E.; Silvestri, G.; Griffin,

D.K. Incidence, Reproductive

Outcome, and Economic Impact of

Reciprocal Translocations in the

Domestic Pig. DNA 2021, 1, 68-76.

https://doi.org/10.3390/dna1020007

Academic Editor: Andrzej Stasiak

Received: 9 September 2021

Accepted: 5 October 2021

Published: 9 October 2021

Publisher's Note: MDPI stays neutral with regard to jurisdictional claims in published maps and institutional affiliations.

Copyright: (c) 2021 by the authors. Licensee MDPI, Basel, Switzerland. This article is an open access article distributed under the terms and conditions of the Creative Commons Attribution (CC BY) license (https:// creativecommons.org/licenses/by/ $4.0 /)$.
School of Biosciences, University of Kent, Canterbury CT2 7NH, UK; cnlewis03@hotmail.com (N.M.L.); c.c.rathje@kent.ac.uk (C.C.R.); cfcr2@kent.ac.uk (C.C.-R.); lmb61@kent.ac.uk (L.M.B.); lkiazim@gmail.com (L.G.K.); beccajennings3@gmail.com (R.L.J.); rebeckyoc@gmail.com (R.E.O.);

G.Silvestri@Kent.ac.uk (G.S.)

* Correspondence: D.K.Griffin@Kent.ac.uk

\begin{abstract}
Pigs (Sus scrofa) have vast economic importance, with pork accounting for over $30 \%$ of the global meat consumption. Chromosomal abnormalities, and in particular reciprocal translocations (RTs), are an important cause of hypoprolificacy (litter size reduction) in pigs. However, these do not necessarily present with a recognizable phenotype and may cause significant economic losses for breeders when undetected. Here, we present a reappraisal of the incidence of RTs across several European pig herds, using contemporary methodology, as well as an analysis modelling the economic impact of these abnormalities. Molecular cytogenetic investigation was completed by karyotyping and/or multiprobe FISH (fluorescence in situ hybridisation) between 2016-2021, testing 2673 animals. We identified 19 types of chromosome abnormalities, the prevalence of these errors in the database was $9.1 \%$, and the estimated incidence of de novo errors was $0.90 \%$. Financial modelling across different scenarios revealed the potential economic impact of an undetected RT, ranging from $£ 69,802$ for an individual affected terminal boar in a commercial farm selling weaned pigs, to $£ 51,215,378$ for a genetics company with an undetected RT in a dam line boar used in a nucleus farm. Moreover, the added benefits of screening by FISH instead of karyotyping were estimated, providing a strong case for proactive screening by this approach.
\end{abstract}

Keywords: chromosome; karyotype; FISH; subtelomere; artificial insemination (AI)

\section{Introduction}

The domestic pig (Sus scrofa) provides 30-40\% of the meat consumed worldwide, making it the leading source of meat protein globally. Additionally, its annual production is projected to increase over the next ten years, in line with an increase in world population [1].

As such, breeding companies are tasked with supporting this demand while increasing profitability, reducing wastage and environmental damage and, simultaneously, ensuring high levels of animal welfare. One of the tools at their disposal is artificial insemination (AI), a technique allowing the distribution of the most promising male genetics across distance (by shipping) and time (extended semen) [2]. Fertility in boars awaiting AI service is routinely estimated by semen analysis [3], which may include computer-assisted methods [4]. However, the ability of these methods to detect non-extreme variation in fertility is limited [5]. Farrowing rates and litter size are also commonly examined following $\mathrm{AI}$, since a decrease in litter size is considered the primary indicator of boars displaying sub-optimal fertility. Nonetheless, reproductive problems take time to identify in any given boar in this way, and the boar may be approaching the end of its reproductive life before robust data on litter sizes is gathered. This analysis is also complicated by the practice, in some countries, of semen pooling, which makes it difficult to trace the litter size performance of a specific sire. 
A major biological issue that causes subfertility in mammals is that of chromosomal abnormalities (mostly balanced reciprocal translocations-RTs), which are relatively common and a primary cause of reduction in litter sizes (hypoprolificacy) in boars [6-8]. RTs of likely de novo origin have been discovered in roughly 1:200 AI boars [9], while a report screening related individuals discovered a prevalence for these errors as high as 1:30 [10]. Indeed, hundreds of different RTs have been identified to date in the pig [11]. Around half of all boars exhibiting hypoprolificacy are the carriers of an RT, despite displaying a normal phenotype and good semen parameters [12]. Carriers of balanced RTs suffer significant reductions in farrowing rates and litter size because these chromosomal abnormalities produce up to $50 \%$ unbalanced gametes during meiosis $[7,9,12,13]$. As such, RTs are heritable and persist in roughly half of the surviving offspring of the carrier. This phenomenon results in the propagation of the issue from generation to generation and can have severe economic consequences for the breeding industry [3].

To the best of our knowledge, however, a comprehensive quantification of this economic impact has yet to be reported in the literature. The modern pig breeding industry can be visualized, simplistically, as a breeding pyramid with three steps: the top of the pyramid is occupied by nucleus herds of purebred animals, followed by multiplication herds, and, finally, commercial herds that aim to farrow and raise pigs to enter the food market [14]. As a result, the severity of the economic impact caused by an RT will depend on which levels of the pyramid are affected.

With the above in mind, the application of screening methods able to identify the fertility issues caused by RTs at a very early stage, and ideally prior to a boar entering a breeding program, is vital. Karyotyping is widely employed as a screening method for chromosomal abnormalities, but the resolution of this technique is limited, and its accuracy is operator dependent. A potential solution is a novel device established by our group as discussed in $\mathrm{O}^{\prime}$ Connor and colleagues [15], where we reported the development of a new screening protocol using fluorescence in situ hybridisation (FISH) based on multiple hybridization of sub-telomeric probes $[7,15]$. FISH-based screening is better suited than karyotyping for detecting small (cryptic) translocations and offers an output less subject to the skill of the operator performing the analysis. As a result, a greater proportion of RTs are detected $[7,15]$.

The aim of this work was to provide a re-appraisal of the incidence of RTs across several European herds, based on a Europe wide screening programme, and to provide a financial analysis of the potential economic impact of RTs on the pig breeding industry. The latter depends on where the RT occurred in the breeding pyramid and thus, we aimed to calculate the impact of RTs in several realistic breeding scenarios. Finally, we calculated the added economic benefit of the increased sensitivity of the FISH screening approach compared to standard karyotyping.

\section{Materials and Methods}

\subsection{Animals}

This work investigated 2673 boars between the years 2016 and 2021. Fresh blood samples were collected in Li-Hep tubes by the breeder via standard phlebotomy as part of their routine veterinarian checks. Blood samples were transported at an ambient temperature and delivered by courier to the University of Kent within $48 \mathrm{~h}$ of collection.

\subsection{Preparation of Chromosome Metaphases and Karyotyping}

The mitotic chromosome preparations were obtained from white blood cell culture, following a previously established protocol [15]. Briefly, the blood samples were incubated for $72 \mathrm{~h}$ in the medium PB-MAX ${ }^{\mathrm{TM}}$ (Gibco, Thermo Fisher Scientific, Waltham, MA, USA) in a final volume of $10 \mathrm{~mL}$ at $37^{\circ} \mathrm{C}$ in a humidified environment and with $5 \%$ $\mathrm{CO}_{2}$. The cells were arrested at the metaphase stage by addition of $10 \mu \mathrm{g} / \mathrm{mL}$ colcemid (Gibco) and further incubation at $37^{\circ} \mathrm{C}$ for $30 \mathrm{~min}$. A $12 \mathrm{~min}$ red blood cell lysis step was then completed by addition of $75 \mathrm{mM} \mathrm{KCl}$, followed by fixation of the resulting white 
blood cell pellet in methanol:acetic acid 3:1 (three changes). Finally, the fixed metaphase samples were dropped onto glass slides and allowed to air-dry in preparation for downstream analysis. SMARTTYPE software (Digital Scientific, Cambridge, UK) was used for karyotyping purposes.

\subsection{Fluorescence In Situ Hybridisation (FISH)}

Fluorescence in situ hybridisation (FISH) was performed using the same "multiprobe device" originally developed by $\mathrm{O}^{\prime}$ Connor and colleagues [15]. The device consists of a glass template slide subdivided in square sections each containing a pair of fluorescently labelled probes targeting the subtelomeric region of the $\mathrm{q}$ and $\mathrm{p}$ arm of a specific chromosome. The probes for the distal q (long) arm were labelled in Texas Red (TR), while the probes for the distal $\mathrm{p}$ (short) arm (or proximal $\mathrm{q}$ arm for acrocentric chromosomes) in FITC (fluorescein isothiocyanate). The device contains individual probe-sets for each of the 18 porcine autosomes, plus one extra set for chromosome $\mathrm{X}$. These devices were acquired from Cytocell Ltd. (Oxford Gene Technology, Cambridge, UK) or produced in-house from intermediate materials provided by the same supplier. FISH experiments were completed following the manufacturer's instructions. In brief, the glass slides hosting the air-dried metaphase preparations were dipped in $70 \%$ acetic acid followed by two washes in $2 \times$ sodium saline citrate (SSC) for $2 \mathrm{~min}$ each. The cells were then dehydrated by ethanol series ( 2 min each in $70 \%, 85 \%$, and $100 \%$ ethanol) at room temperature. The multiprobe devices were warmed at $37^{\circ} \mathrm{C}$ and each of their squares was primed with $1 \mu \mathrm{L}$ hybridization buffer (Hyb I, Cytocell). The glass slide hosting the metaphase preparations and the multiprobe device where then pressed together and DNA denaturation was carried out on a hot plate at $75^{\circ} \mathrm{C}$ for $5 \mathrm{~min}$. Following denaturation, the samples were incubated overnight at $37^{\circ} \mathrm{C}$ in a humidified environment. The multiprobe devices were then removed and the sample slides were rinsed for $2 \mathrm{~min}$ in $0.4 \times \mathrm{SSC}$ at $72{ }^{\circ} \mathrm{C}$, followed by a second rinse of $30 \mathrm{~s}$ in $2 \times$ SSC $/ 0.05 \%$ Tween 20 at room temperature. Finally, the chromosomes were stained using the DAPI containing mounting medium Vectashield (Vector Labs, Burlingame, CA, USA).

\subsection{Microscopy and Image Analysis}

The images were captured using a BX61 epifluorescence microscope (Olympus, Tokyo, Japan) with a cooled CCD (charge-coupled device) camera using standard DAPI, FITC and TR filter sets. The software used to record and store the images was SmartCapture (version 3, Digital Scientific, Cambridge, UK). Each chromosome was tested for the presence of a translocation, which could be identified by the absence of the expected pattern of a red signal for its $q$ arm and a green signal for its $p$ (or proximal $q$ ) arm. RTs were confirmed by the presence of a misplaced signal on both of the chromosomes involved in the translocation.

\subsection{Economic Impact Estimation Model}

Figures were established based on published literature, published current monetary values concerning the domestic pig market in the UK (between August 2020 and August 2021, as further reported in Supplementary Table S1) [16], and five interviews with managers and stakeholders within the global pig breeding industry. For the monetary figures, the value of a standard commercial pig was used, i.e., a pig the price of which does not attract a premium due to its breed, provenance, or specific rearing conditions. The parameters employed in the economic calculations are reported in Table 1. In each scenario, we made use of the following assumptions: all the mating were by AI, there was no semen pooling, the affected animal was mated to full capacity/requirements, $50 \%$ of the live offspring of an affected parent would be an RT carrier itself, and importantly, the affected breeder was unable to mitigate the losses by culling the affected offspring and/or replacing the animals lost. 
Calculations were then designed to show how many pigs or $\mathrm{kg}$ of meat could be lost due to the impact of an RT, and those numbers were then converted into a currency value. The reported confidence intervals were calculated based on the variability of the monetary figures alone. From the information available and looking at context parameters such as business type and location of the animal in the breeding pyramid, a potential financial impact was calculated for various scenarios.

Table 1. Parameters employed in the economic impact estimator model. Five interviews were conducted with managers and stakeholders within the global pig breeding industry.

\begin{tabular}{|c|c|c|c|}
\hline Parameter & Definition & Evidence & Key Figures \\
\hline Boar productivity & $\begin{array}{l}\text { How many sperm doses and piglets } \\
\text { are produced by a boar }\end{array}$ & interviews & $\begin{array}{l}1872 \text { semen doses per year } \\
33.1 \text { semen doses per week }\end{array}$ \\
\hline Number of matings & $\begin{array}{l}\text { Total matings by a single boar per } \\
\text { year, each mating using multiple } \\
\text { semen doses }\end{array}$ & interviews & $\begin{array}{c}\text { 2.1 AI (artificial insemination) doses } \\
\text { per mating } \\
\text { 820.1 mattings per year }\end{array}$ \\
\hline Boar prevalence & $\begin{array}{c}\text { The maximum likely proportion of } \\
\text { nucleus farm sows inseminated with } \\
\text { a specific boar }\end{array}$ & interviews & $e^{2}$ \\
\hline Farrowing rate & $\begin{array}{l}\text { The proportion of sows that are } \\
\text { served that go on to farrow }\end{array}$ & [17] & $85-90 \%$ \\
\hline Farrowing per year & $\begin{array}{c}\text { The number of farrowings per sow } \\
\text { per year }\end{array}$ & $\begin{array}{l}\text { interviews } \\
\quad[18]\end{array}$ & 2.2 to 2.39 per sow \\
\hline Total born alive & Total number of live piglets in a litter & $\begin{array}{l}\text { interviews } \\
{[19-22]}\end{array}$ & 8 to 16 piglets \\
\hline Mortality & $\begin{array}{l}\text { Piglets dying before reaching } \\
\text { reproductive age or slaughter weight } \\
\text { (as appropriate) }\end{array}$ & {$[20,23,24]$} & $\begin{array}{l}5 \text { to } 35 \% \text { pre-weaning } \\
4 \text { to } 8 \% \text { post-weaning }\end{array}$ \\
\hline Dam selection rate & $\begin{array}{c}\text { Proportion of dams that are selected } \\
\text { to become parents of the } \\
\text { next generation }\end{array}$ & interviews & $70 \%$ \\
\hline Sire selection rate & $\begin{array}{l}\text { Proportion of Great Grandparent } \\
\text { (GGP) level boars that are selected to } \\
\text { become sires to commercial pigs }\end{array}$ & interviews & 1.54 per litter \\
\hline Availability rate & $\begin{array}{l}\text { Proportion of females cycling and } \\
\text { available for breeding }\end{array}$ & interviews & $90 \%$ \\
\hline Corrective action time & $\begin{array}{l}\text { Time interval between the first } \\
\text { mating of an RT (reciprocal } \\
\text { translocation) carrier boar and the } \\
\text { discovery of a reduction in litter sizes } \\
\text { for this animal }\end{array}$ & interviews & $\begin{array}{l}16.6 \text { weeks for first litters } \\
\geq 19.6 \text { weeks before sufficient data } \\
\text { is gathered }\end{array}$ \\
\hline Market values & $\begin{array}{c}\text { Estimated monetary value of a } \\
\text { commercial pig in British } \\
\text { pounds (GBP) }\end{array}$ & [16] & $\begin{array}{c}£ 39.83 \pm 0.81 \text { per weaner pig } \\
£ 1.5 \pm 0.02 \text { per } \mathrm{Kg} \text { of meat } \\
88.79 \pm 0.42 \mathrm{Kg} \text { average } \\
\text { carcass weight }\end{array}$ \\
\hline
\end{tabular}

\subsection{Data Analysis}

The data were collected and curated on Microsoft Excel (Microsoft, Redmond, WA, USA). Whenever possible, the data were reported as averages with their $95 \%$ Confidence Interval (C.I.).

\section{Results}

\subsection{Prevalence and Incidence of Chromosomal Errors and RTs}

Over the study period, we assessed $n=2673$ animals. Among this sample population, $n=2148$ animals were screened using multiprobe FISH (Figure 1), and $n=525$ by karyotyping. We identified 19 types of chromosomal errors, of which 17 were RTs, as presented in Table 2. The total number of affected animals was $n=243$ (an uncorrected error prevalence 
of 9.1\%); more specifically, $n=236(8.8 \%)$ had an RT, $n=5(0.19 \%)$ were $\mathrm{XX} / \mathrm{XY}$ chimeras, and $n=2(0.07 \%)$ carried a complex translocation.

However, these figures cannot be taken at face value as an indication of the true incidence of de novo chromosomal errors across European pig herds as many of the RTs reported were detected among related individuals. By disregarding "duplicated" abnormalities arising in close relatives, we estimated the actual incidence of de novo chromosomal translocations to be $0.90 \%(n=22 / 2445,95 \%$ C.I. $0.60-1.36 \%)$.
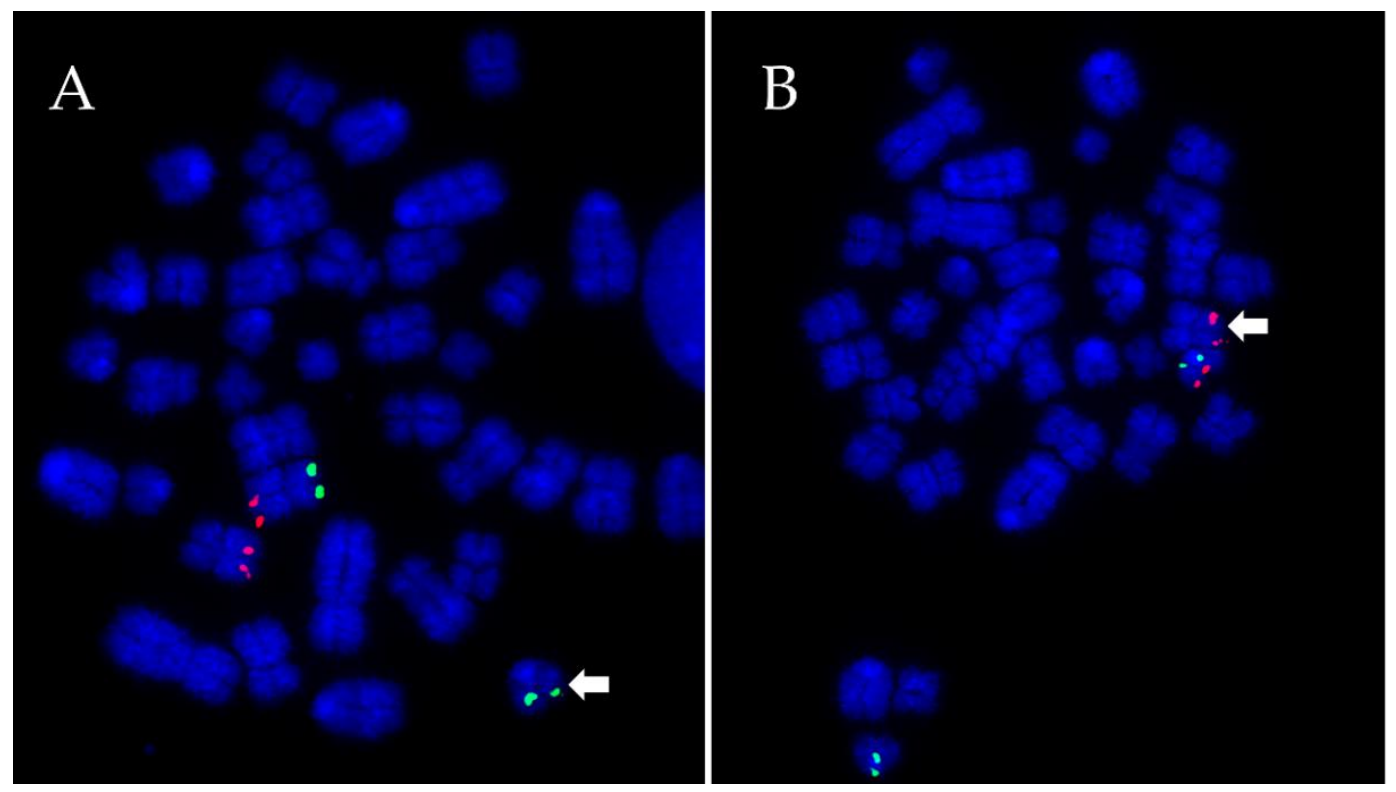

Figure 1. (A) Probes for 9p (green) and 9q (red) both correctly hybridize to the normal chromosome 9; a translocation is detected due to the second p-arm signal localizing on chromosome 18 instead (arrow). (B) Probes for 18p (green) and 18q (red) both correctly hybridize to the normal chromosome 18; a translocation is detected due to the second q-arm signal localizing on chromosome 9 instead (arrow). Together, the two images establish this was a case of reciprocal translocation (RT) $\mathrm{t}(9 ; 18)$. DNA counterstained in DAPI (blue). Total magnification $1000 \times$.

Table 2. Chromosomal errors detected. The analysis took place between 2016 and 2021 and assessed $\mathrm{n}=2673$ individuals. A total of 19 chromosomal error types (17 independent RTs) were diagnosed from $n=243$ affected animals using either fluorescence in situ hybridization (FISH) or karyotyping.

\begin{tabular}{ccc}
\hline Chromosomal Error & Total Number of Cases & De Novo Cases \\
\hline $\mathfrak{t}(1 ; 2)$ & 138 & 1 \\
$\mathrm{t}(1 ; 3)$ & 1 & 1 \\
$\mathrm{t}(1 ; 13)$ & 1 & 1 \\
$\mathrm{t}(1 ; 17)$ & 1 & 1 \\
$\mathrm{t}(2 ; 14)$ & 1 & 1 \\
$\mathrm{t}(3 ; 7)$ & 1 & 1 \\
$\mathrm{t}(3 ; 9)$ & 3 & 1 \\
$\mathrm{t}(3 ; 17)$ & 1 & 1 \\
$\mathrm{t}(4 ; 5)$ & 15 & 2 \\
$\mathrm{t}(5 ; 6)$ & 1 & 1 \\
$\mathrm{t}(7 ; 10)$ & 21 & 2 \\
$\mathrm{t}(9 ; 10)$ & 1 & 1 \\
$\mathrm{t}(9 ; 12)$ & 1 & 1 \\
$\mathrm{t}(9 ; 13)$ & 2 & 2 \\
$\mathrm{t}(9 ; 18)$ & 25 & 1 \\
$\mathrm{t}(10 ; 15)$ & 1 & 1 \\
$\mathrm{t}(16 ; 17)$ & 1 & 1 \\
$X X / X Y$ chimeric & 5 & 5 \\
other, complex & 2 & 2 \\
\hline
\end{tabular}




\subsection{The Economic Costs of RTs}

When RTs occur among the breeding stock, farming businesses accrue economic losses in the form of missed revenue due to the reduction in litter sizes resulting in animals (and their offspring, if applicable) "missing" from their herds. Having taken the parameters discussed in Table 1 into consideration, the economic impact of RTs was found to vary substantially according to the scenario considered. The most important factors affecting the outcome were at which point in the breeding pyramid where the RT arose (i.e., in the parent, grandparent, or great-grandparent of the pig meant to enter the food market), and the operation model adopted. In this section, the losses resulting from RT based hypoprolificacy are considered across five key scenarios:

1. A commercial herd adopting a farrow to wean business model;

2. A commercial herd adopting a farrow to finish business model;

3. A multiplier herd;

4. A nucleus herd producing terminal boars for use at stud;

5. A nucleus herd, producing dam line sows.

A more extensive definition for each scenario is given in Table 3, whilst the results of the economic impact analysis are presented in Table 4. A full calculation breakdown for each case is presented in Supplementary Table S1. The supplementary table also presents a detailed calculation for the estimated number of mattings that can be obtained from a single AI boar, a figure which forms the basis of the following calculations.

Table 3. Description of the five key scenarios considered in the economic impact analysis.

\begin{tabular}{|c|c|}
\hline Key Scenario & Scenario Description \\
\hline Commercial herd (farrow to wean) & $\begin{array}{l}\text { A commercial level farm specializing in selling weaned pigs of about } 7 \mathrm{~kg} \text { in weight, } \\
\text { purchasing AI semen doses from a stud farm. The RT is affecting one of the boars supplying } \\
\text { the AI doses. }\end{array}$ \\
\hline Commercial herd (farrow to finish) & $\begin{array}{c}\text { This scenario mimics the previous one, but instead of selling piglets, this farm raises them to } \\
\text { slaughter weight. }\end{array}$ \\
\hline Multiplier herd & $\begin{array}{l}\text { A multiplier herd is made up of purebred animals producing crossbred sows for } \\
\text { commercial production. An RT affects a boar used to create these commercial sows. The } \\
\text { calculation considers the cascade effect on the next generation of commercial level pigs. }\end{array}$ \\
\hline Nucleus herd (terminal line) & $\begin{array}{l}\text { A nucleus herd producing sires, where one of the boars is affected by an RT. This calculation } \\
\text { considers the effects on the male's offspring, and then on the generation of commercial pigs } \\
\text { deriving from it. }\end{array}$ \\
\hline Nucleus herd (dam line) & $\begin{array}{l}\text { A nucleus herd aiming to produce dam line sires, where one of the boars is affected by an } \\
\text { RT. This calculation considers the effects of the female and male offspring on the next } \\
\text { generation of multiplier pigs and, further to that, commercial level pigs. }\end{array}$ \\
\hline
\end{tabular}

Table 4. Analysis of the economic impact of an RT across five key scenarios. The potential monetary losses are estimated in British Pounds (GBP). Figures are presented with their $95 \%$ C.I. based on the fluctuation of the monetary value of pigs (and pork) in the UK during August 2020-August 2021.

\begin{tabular}{cc}
\hline Key Scenario & Average Economic Impact (GBP) \\
\hline Commercial herd (farrow to wean) & $£ 69,802 \pm 1413$ \\
Commercial herd (farrow to finish) & $£ 222,199 \pm 3252$ \\
Multiplier herd & $£ 1,400,833 \pm 28,351$ \\
Nucleus herd (terminal line) & $£ 4,442,945 \pm £ 89,919$ \\
Nucleus herd (dam line) & $£ 51,215,378 \pm £ 1,036,525$ \\
\hline
\end{tabular}

\subsection{Mitigating Losses by Proactive RT Screening}

The purpose of this section is to evaluate the financial benefit of either karyotyping or FISH based RT screening programmes. The reported incidence of RTs following karyotyping investigation is $0.47 \%$ [9] but in the present work, we detected an incidence of $0.90 \%$, which, based on previously published findings [7], we suggest is thanks to FISH being a 
more sensitive detection method, especially when cryptic translocations are present. As such, it may be speculated that karyotyping will detect approximatively one new translocation for every 213 screened boars, while FISH will detect a new RT for every 111 boars under the assumptions presented here, or in every 142 boars under the more conservative guidelines presented in our previous work [7].

Due to the large number of dams served by a single male in AI based breeding, all sires should be screened for RTs as long as the cost of performing this does not exceed the potential economic impact of an undetected RT (as presented previously in Table 4). With this in mind, and considering the scenarios above, it can be concluded that terminal sires intended to become parents to commercial slaughter pigs should be screened for RTs as long as the total cost of screening does not exceed $£ 629$ ( $£ 69,802$ divided by 111$)$ per boar in a farrow-to-wean scenario or $£ 2002$ ( $£ 222,199$ divided by 111) per boar in a farrow-to-finish farm. Our current understanding of the screening market suggests these targets are certainly achievable.

In particular, FISH screening appears more beneficial than karyotyping as it offers higher potential savings: between $£ 492$ and $£ 629$ per screened boar, instead of $£ 328$ for karyotyping under the farrow to wean scenario (the most conservative scenario), with the gap between the two methodologies becoming dramatically wider as the potential economic impact of an RT increases. As such, under the average/realistic conditions described in the present work, it would plausibly always be economically beneficial for breeders to opt for the more sensitive FISH approach to screen all boars selected to become sires, due to the very significant losses associated with missing an RT at all levels of the breeding pyramid.

\section{Discussion}

In 2019, the global pig production industry exceeded a total net worth of 396 billion US dollars and is projected to exceed 500 billion by 2027 [25]. It has long been established that chromosome abnormalities, and in particular RTs, can cause hypoprolificacy in the pig, which can subsequently incur significant losses for the pig breeding industry. To the best of our knowledge, this is the first report of its kind to provide a realistic quantification of those losses, which we found can amount to several million GBP (Euros or Dollars). Therefore, the impact of this work has global ramifications, not only financially but also environmentally, as use of sows to produce suboptimal litter sizes means that unnecessary waste is produced by them [26]. The environmental impact of RT screening will form the basis of future studies.

Under the stated assumptions, our figures are nonetheless, conservative as they do not take into account any potential loss in reputation or customer base that a breeder might face as a result, nor the costs involved with any attempt to replace the "missing" animals (if at all possible, due to the likely higher genetic merit of the new generation). It is also interesting to note that our calculations highlight how the more efficient a breeding business becomes (i.e., better farrowing rates, lower mortality, higher litter sizes) the more severe the economic impact of an RT will be.

Across the global pig industry, breeding practices, average herd performance (farrowing rate, mortality, litter size and so on), and monetary values, display a large variability. As such, it is not practical nor useful to produce a single scenario calculation that will accurately portray the economic impact of RTs for any specific breeder. Despite this, we believe the five scenarios we proposed encompass a wide range of possible real-life cases and their underlying calculations (that we present as supplementary data) can easily be adapted to model any actual occurrence. We encourage companies to do this for their own particular purposes.

Our work has also shown that chromosomal issues such as RTs persist in pig herds, despite widespread eradication efforts. Boars that carry an RT usually present with a normal phenotype, so that, without an efficient and proactive screening programme, the effects of these abnormalities may only be appreciated after the boar has produced 
significantly smaller litters [3] and has therefore already caused significant economic disruption. Whilst the reported incidence of RTs is $0.47 \%$ [9], here we discovered a value of $0.90 \%$. Whilst this is likely the result of the employment of FISH based screening methodology [7], other factors such as sample size, herd characteristics, or the length of time the herds have been subject to cytogenetic screening prior to our study, may have influenced this figure.

In a recent publication, we estimated that at a minimum of $50 \%$ more abnormalities would be detected by FISH compared to karyotyping [7]. A rough calculation therefore is that only two thirds of the above calculated benefits of RT screening will be realized by karyotyping alone, leading to net losses of between tens of thousands to tens of millions GBP/Dollars/Euros (or equivalent) if multiprobe FISH is not employed. Our modelling therefore demonstrates that a multi-probe FISH-based approach is beneficial for breeders, despite a modest increase in comparative cost per sample, compared to karyotyping.

\section{Conclusions}

This study makes a very strong case for the application of a proactive, rigorous and worldwide RT screening programme. Karyotyping is widely employed in both cytogenetic and clinical applications and is still considered the standard method for the detection of a wide variety of chromosomal abnormalities, including, for example, inversions and both balanced and unbalanced translocations. As we have shown, its application to pig breeding programmes has clear economic benefits. Nonetheless, we suggest that the higher sensitivity of FISH screening makes it a very attractive complement or even alternative to classic screening methods, and its application would likely be economically justifiable to breeders.

Supplementary Materials: The following are available online at https:/ /www.mdpi.com/article/10 $.3390 /$ dna1020007/s1, Table S1: Source data and full calculation.

Author Contributions: Conceptualization, N.M.L., R.E.O. and D.K.G.; methodology, N.M.L., C.C.R., C.C.-R., L.M.B., L.G.K., R.L.J., R.E.O. and G.S.; validation, L.G.K., R.L.J. and R.E.O.; formal analysis, N.M.L. and G.S.; investigation, N.M.L., C.C.R., C.C.-R., L.M.B., L.G.K., R.L.J. and G.S.; resources, N.M.L.; data curation, C.C.R., C.C.-R. and G.S.; writing-original draft preparation, N.M.L., C.C.R., G.S. and D.K.G.; writing-review \& editing, G.S. and D.K.G.; supervision, D.K.G.; funding acquisition, D.K.G. All authors have read and agreed to the published version of the manuscript.

Funding: This work was supported by the BBSRC grant BB/P020054/1.

Institutional Review Board Statement: Not applicable.

Informed Consent Statement: Not applicable.

Data Availability Statement: Source data and full calculations are presented in Supplementary Table S1.

Acknowledgments: The authors would like to thank Craig Lewis (PIC) for his helpful comments in preparing this manuscript.

Conflicts of Interest: The funders had no role in the design of the study, in the collection, analyses, or interpretation of data, in the writing of the manuscript, nor in the decision to publish the results. The authors declare no conflict of interest, however point out that multi-probe FISH screening is a routine procedure carried out by the University of Kent laboratories and carries a cost to any company wishing to take advantage of the benefits offered by it. All income is however fed back into further research and development, and to support graduate students. The University of Kent is a not-for-profit organization, please contact the corresponding author for any screening enquiries.

\section{References}

1. FAO. FAOSTAT. 2019. Available online: http:/ / www.fao.org/faostat/en/\#home (accessed on 26 December 2019).

2. Knox, R. Artificial Insemination in Pigs Today. Theriogenology 2016, 85, 83-93. [CrossRef] [PubMed] 
3. Rodríguez, A.; Sanz, E.; De Mercado, E.; Gómez, E.; Martín, M.; Carrascosa, C.; Gomez-Fidalgo, E.; Villagomez, D.; SanchezSanchez, R. Reproductive Consequences of a Reciprocal Chromosomal Translocation in Two Duroc Boars used to Provide Semen for Artificial Insemination. Theriogenology 2010, 74, 67-74. [CrossRef] [PubMed]

4. Broekhuijse, M.L.W.J.; Šoštarić, E.; Feitsma, H.; Gadella, B.M. Application of computer-assisted semen analysis to explain variations in pig fertility1. J. Anim. Sci. 2012, 90, 779-789. [CrossRef] [PubMed]

5. Kamphuis, C.; Duenk, P.; Veerkamp, R.F.; Visser, B.; Singh, G.; Nigsch, A.; De Mol, R.M.; Broekhuijse, M.L.W.J. Machine Learning to Further Improve the Decision which Boar Ejaculates to Process into Artificial Insemination Doses. Theriogenology 2020, 144, 112-121. [CrossRef] [PubMed]

6. Jennings, R.L.; Griffin, D.K.; O'Connor, R.E. A New Approach for Accurate Detection of Chromosome Rearrangements that Affect Fertility in Cattle. Animals 2020, 10, 114. [CrossRef] [PubMed]

7. O'Connor, R.; Kiazim, L.; Rathje, C.; Jennings, R.; Griffin, D. Rapid Multi-Hybridisation FISH Screening for Balanced Porcine Reciprocal Translocations Suggests a Much Higher Abnormality Rate Than Previously Appreciated. Cells 2021, 10, 250. [CrossRef] [PubMed]

8. Shams, F.; D'Souza, D.; Ezaz, T. Balanced Chromosomal Rearrangements Associated with Hypoprolificacy in Australian Boars (Sus scrofa domesticus). Cells 2021, 10, 2000. [CrossRef] [PubMed]

9. Ducos, A.; Berland, H.-M.; Bonnet, N.; Calgaro, A.; Billoux, S.; Mary, N.; Garnier-Bonnet, A.; Darré, R.; Pinton, A. Chromosomal Control of Pig Populations in France: 2002-2006 Survey. Genet. Sel. Evol. 2007, 39, 583. [CrossRef] [PubMed]

10. Sánchez-Sánchez, R.; Gómez-Fidalgo, E.; Pérez-Garnelo, S.; Martín-Lluch, M.; De la Cruz-Vigo, P. Prevalence of Chromosomal Aberrations in Breeding Pigs in Spain. Reprod. Domest. Anim. 2019, 54, 98-101. [CrossRef] [PubMed]

11. Danielak-Czech, B.; Kozubska-Sobocińska, A.; Smołucha, G.; Babicz, M. Breeding and Economic Aspects of Cytogenetic Screening Studies of Pigs Qualified for Reproduction. Animals 2020, 10, 1200. [CrossRef] [PubMed]

12. Rodríguez-Gil, J.E.; Estrada, E. Artificial Insemination in Boar Reproduction. In Boar Reproduction; Bonet, S., Casas, I., Holt, W.V., Yeste, M., Eds.; Springer: New York City, NY, USA, 2013; pp. 589-607.

13. Grahofer, A.; Letko, A.; Häfliger, I.M.; Jagannathan, V.; Ducos, A.; Richard, O.; Peter, V.; Nathues, H.; Drögemüller, C. Chromosomal Imbalance in Pigs Showing a Syndromic Form of Cleft Palate. BMC Genom. 2019, 20, 31068123. [CrossRef] [PubMed]

14. Visscher, P.; Pong-Wong, R.; Whittemore, C.; Haley, C. Impact of Biotechnology on (Cross)Breeding Programmes in Pigs. Livest. Prod. Sci. 2000, 65, 57-70. [CrossRef]

15. O'Connor, R.; Fonseka, G.; Frodsham, R.; Archibald, A.; Lawrie, M.; Walling, G.A.; Griffin, D.K. Isolation of Subtelomeric Sequences of Porcine Chromosomes for Translocation Screening Reveals Errors in the Pig Genome Assembly. Anim. Genet. 2017, 48, 395-403. [CrossRef] [PubMed]

16. Agriculture and Horticulture Development Board (AHDB). Available online: https://ahdb.org.uk/ (accessed on 30 August 2021).

17. Young, B.; Dewey, C.E.; Friendship, R.M. Management Factors Associated with Farrowing Rate in Commercial Sow Herds in On-tario. Can. Vet. J. 2010, 51, 185-189. [PubMed]

18. Pierozan, C.; Callegari, M.; Dias, C.; de Souza, K.; Gasa, J.; da Silva, C. Herd-Level Factors Associated with Piglet Weight at Weaning, Kilograms of Piglets Weaned per Sow per Year and Sow Feed Conversion. Animals 2020, 14, 1283-1292. [CrossRef] [PubMed]

19. Aherne, F.; Kirkwood, R. Factors Affecting Litter Size. Pig Articles from The Pig Site 2001. Available online: https://www. thepigsite.com/articles/factors-affecting-litter-size (accessed on 30 August 2021).

20. McGlone, J.; Pond, W.G. Pig Production: Biological Principles and Applications; Delmar Learning, Inc.: Clifton Park, NY, USA, 2003.

21. Freyer, G. Maximum Number of Total Born Piglets in a Parity and Individual Ranges in Litter Size Expressed as Specific Charac-teristics of Sows. J. Anim. Sci. Technol. 2018, 60, 1-7. [CrossRef]

22. Nowak, B.; Mucha, A.; Moska, M.; Kruszyński, W. Reproduction Indicators Related to Litter Size and Reproduction Cycle Length Among Sows of Breeds Considered Maternal and Paternal Components Kept on Medium-Size Farms. Animals 2020, 10, 1164. [CrossRef] [PubMed]

23. Mainau, E.; Temple, D.; Manteca, X. Pre-Weaning Mortality in Piglets; Farm Animal Welfare Education Centre: Barcelona, Spain, 2015.

24. Gebhardt, J.T.; Tokach, M.D.; Dritz, S.S.; DeRouchey, J.M.; Woodworth, J.C.; Goodband, R.D.; Henry, S.C. Postweaning Mortality in Commercial Swine Production II: Review of Infectious Contributing Factors. Transl. Anim. Sci. 2020, 4, 485-506. [CrossRef] [PubMed]

25. BCC Research. Food and Beverages Market. Research Report; BCC Research: Wellesley, MA, USA, 2019.

26. Dourmad, J.; Ryschawy, J.; Trousson, T.; Bonneau, M.; Gonzalez, J.; Houwers, H.; Hviid, M.; Zimmer, C.; Nguyen, T.L.T.; Morgensen, L. Evaluating Environmental Impacts of Contrasting Pig Farming Systems with Life Cycle Assessment. Animals 2014, 8, 2027-2037. [CrossRef] [PubMed] 